University of Nebraska - Lincoln

DigitalCommons@University of Nebraska - Lincoln

Publications from USDA-ARS / UNL Faculty

U.S. Department of Agriculture: Agricultural

Research Service, Lincoln, Nebraska

2011

Comparative cryopreservation of avian spermatozoa: Benefits of non-permeating osmoprotectants and ATP on turkey and crane sperm cryosurvival

\author{
Juan M. Blanco \\ Aquila Foundation and Center for the Studies on Iberian Raptors \\ Julie A. Long \\ USDA, ARS, ANRI, ABBL, julie.long@ars.usda.gov \\ George Gee \\ Patuxent Wildlife Research Center \\ David E. Wildt \\ Conservation \& Research Center \\ Ann M. Donoghue \\ USDA, ARS, PPPSRU
}

Follow this and additional works at: https://digitalcommons.unl.edu/usdaarsfacpub

Part of the Agricultural Science Commons

Blanco, Juan M.; Long, Julie A.; Gee, George; Wildt, David E.; and Donoghue, Ann M., "Comparative cryopreservation of avian spermatozoa: Benefits of non-permeating osmoprotectants and ATP on turkey and crane sperm cryosurvival" (2011). Publications from USDA-ARS / UNL Faculty. 834.

https://digitalcommons.unl.edu/usdaarsfacpub/834

This Article is brought to you for free and open access by the U.S. Department of Agriculture: Agricultural Research Service, Lincoln, Nebraska at DigitalCommons@University of Nebraska - Lincoln. It has been accepted for inclusion in Publications from USDA-ARS / UNL Faculty by an authorized administrator of DigitalCommons@University of Nebraska - Lincoln. 


\title{
Comparative cryopreservation of avian spermatozoa: Benefits of non-permeating osmoprotectants and ATP on turkey and crane sperm cryosurvival ${ }^{\text {is }}$
}

\author{
Juan M. Blanco ${ }^{\mathrm{a}, \mathrm{b}}$, Julie A. Long ${ }^{\mathrm{b}, *}$, George Gee ${ }^{\mathrm{c}}$, David E. Wildt ${ }^{\mathrm{d}}$, Ann M. Donoghue ${ }^{\mathrm{e}}$ \\ a Aquila Foundation and Center for the Studies on Iberian Raptors, CERI Toledo, Spain \\ b USDA, ARS, ANRI, ABBL, Beltsville, MD 20705, United States \\ c Patuxent Wildlife Research Center, Laurel, MD 20708, United States \\ d Center for Species Survival, Smithsonian's National Zoological Park, Conservation E Research Center, Front Royal, VA 22630, United States \\ e USDA, ARS, PPPSRU, Fayetteville, AR 72701, United States
}

\section{A R T I C L E I N F O}

\section{Article history:}

Received 24 May 2010

Received in revised form

19 November 2010

Accepted 10 December 2010

Available online 17 December 2010

\section{Keywords:}

Poultry sperm

DMA

Trehalose

Sucrose

Betaine hydrochloride

\begin{abstract}
A B S T R A C T
A comparative approach was used to evaluate the cryosurvival of turkey and crane sperm frozen in a dimethylacetamide (DMA) cryodiluent supplemented with osmoprotectants and ATP. A range (6-26\%) of DMA concentrations was used alone or in combination with $\operatorname{ATP}(30,60$ or $118 \mathrm{mM})$ or one of the following osmoprotectants: (1) sucrose (turkey, $8.0 \%$; crane, 5.0\%); (2) 5.0\% sucrose and 5.0\% trehalose; or (3) betaine hydrochloride $(0.1,0.2$ or $0.4 \mathrm{mM}$ ). The viability of thawed sperm was assessed using the nigrosin-eosin stain and sperm motility was determined using the hanging-drop technique. For semen frozen only with DMA, post-thaw sperm motility was greatest $(P<0.05)$ for the $6.0 \%, 10.0 \%$ and $18 \%$ concentrations, regardless of species. Turkey sperm frozen with the sucrose/trehalose combination had greater $(P<0.05)$ post-thaw motility for all DMA treatments compared to DMA alone. The lowest concentration of the osmoprotectant betaine hydrochloride substantially improved turkey sperm viability post-thaw in all treatments compared to DMA alone $(P<0.05)$. The post-thaw motility of crane sperm was improved $(P<0.05)$ with a combination of $18.0 \%, 24.0 \%$ or $26.0 \%$ DMA and $30 \mathrm{mM}$ ATP. Moreover, in the presence of osmoprotectants, crane sperm motility decreased as the osmoprotectant concentration increased. The lowest concentration of ATP also improved crane sperm viability post-thaw, especially for DMA concentrations $18 \%$ or greater. The combination of sucrose and trehalose improved $(P<0.05)$ crane sperm viability only with $6 \%$ and $10 \%$ DMA. These data affirm that there are avian-specific differences in sperm survival after cryopreservation and suggest that post-thaw survival can be enhanced by including species-based osmoprotectant/ATP combinations in a cryodiluent where DMA is the cryoprotectant.
\end{abstract}

Published by Elsevier B.V.

\footnotetext{
is This study was supported by the USDA Foreign Agricultural Services Project \#SP 33; The Patuxent Wildlife Research Center, USGS; The Junta de Comunidades de Castilla-La Mancha, the Smithsonian Institution/British Airways partnership; The Smithsonian Women's Committee; and the Aquila Foundation.

* Corresponding author. Tel.: +1 3015048580.

E-mail address: julie.long@ars.usda.gov (J.A. Long).
}

\section{Introduction}

Despite decades of extensive research on the use of permeating cryoprotectants (Sexton, 1975; Oderkirk and Buckland, 1977; Sexton, 1980; Tselutin et al., 1999; Blanco et al., 2000; Tai et al., 2001; Chełmońska et al., 2006; Kowalczyk, 2008), survival of avian sperm after freezing/thawing procedures remains highly variable. Sperm cryosurvival has been improved in various mammalian 
species by combining permeating cryoprotectants, like dimethylacetamide (DMA), with natural osmoprotectants that do not penetrate the plasma membrane, such as sucrose or trehalose (bull, Woelders et al., 1997; rabbit, Dalimata and Graham, 1997; mouse, Thompson et al., 2001; goat, Aboagla and Terada, 2003; dog, Yamashiro et al., 2007; boar, Gutiérrez-Pérez et al., 2009). The combination of permeating cryoprotectant and non-permeating osmoprotectant protects cryopreserved cells by different mechanisms. Penetrating cryoprotectants increase membrane fluidity through rearrangement of membrane lipid and protein, resulting in greater dehydration at lower temperatures and reduced intracellular ice formation (Holt, 2000). In contrast, osmoprotectants are low molecular weight, hydrophilic, nontoxic molecules that help a cell stabilize its concentration of internal solutes under osmotic stress (Cleland et al., 2004). Because of the inability to diffuse across the plasma membrane, these non-permeating substances create an osmotic pressure that lowers the freezing temperature of the medium and decreases extracellular ice formation (Aisen et al., 2002), thereby providing an additive protective effect.

Most living organisms respond to osmotic stress by producing osmoprotectants or compatible solutes that help the cell's cytoplasm maintain an equivalent osmotic pressure with the external environment while avoiding greater intracellular salt concentrations (Csonka and Hanson, 1991). For example, trehalose is synthesized when unicellular organisms are exposed to heat, cold, oxidation or desiccation. To date, this sugar has not been found in higher vertebrates (Jain and Roy, 2009) and its utility for cryopreserving avian sperm has not been examined; although sucrose has received some attention as an osmoprotectant for avian sperm (Sexton, 1975). Betaine is another natural osmoprotectant found in many bacteria (Lippert et al., 1993) that effectively reduces leakage from liposomes during freeze-thawing (Lloyd et al., 1994). The cryoprotective properties of betaine hydrochloride have been demonstrated for ram (SánchezPartida et al., 1992), stallion (Trimeche et al., 1999) and bull (Zhang et al., 2001) sperm, but not yet for avian species.

Another innovation recently considered is the addition of adenosine triphosphate (ATP) to the cryodiluent. The freeze/thaw cycle damages both avian sperm structure and function, largely the processes required for energetic maintenance including glycolysis, the citric acid cycle and the respiratory chain (Ochkur et al., 1994). Assuming that ATP depletion may occur during the re-warming phase (Holt et al., 1992) and that incorporation of exogenous ATP occurs coincident with membrane structural rearrangements, the potential of supplemental ATP improving the viability of thawed sperm seems plausible. In fact, extracellular ATP increases the motility and fertility of frozen/thawed murine (Rodríguez-Miranda et al., 2008) and human (Edwards et al., 2007) sperm.

Based on known differences in the osmotic tolerance of turkey and crane sperm (Blanco et al., 2008), these two species were used in the present study to further delineate species-specific sensitivity to sperm cryopreservation while exploring the possible benefits of supplemental ATP
Table 1

Components of crane sperm cryodiluent ( $\mathrm{pH} 6.65 ; 371 \mathrm{mOsm}$; Blanco et al., 2008).

\begin{tabular}{llr}
\hline Component & $\begin{array}{l}\text { Amount } / 100 \mathrm{~mL} \\
\text { distilled } \mathrm{H}_{2} \mathrm{O}(\mathrm{g})\end{array}$ & $\begin{array}{r}\text { Molar } \\
\text { equivalent }\end{array}$ \\
\hline D-Fructose & 1.15 & $63.8 \mathrm{mM}$ \\
Sodium glutamate & 2.1 & $112.1 \mathrm{mM}$ \\
Polyvinylpyrrolidone & 0.3 & $8.3 \mu \mathrm{M}$ \\
Betaine hydrochloride & 0.2 & $13.0 \mathrm{mM}$ \\
Potassium acetate & 0.5 & $50.9 \mathrm{mM}$ \\
\hline
\end{tabular}

and various non-permeating osmoprotectants in a DMAbased cryodiluent.

\section{Materials and methods}

\subsection{Species/animals used and semen collection}

Sexually mature turkeys (Meleagris gallopavo; $n=40$ ) were housed indoors in floor-pens (10 males/pen) and maintained under an artificial photoperiod (14h L:10 h D) at the Beltsville Agricultural Research Center. Sandhill cranes (Grus canadensis; $n=13$ ) were part of a captive population at the Patuxent Wildlife Research Center, and all semen donors were paired with sexually active females with a history of reproductive success. Crane pairs were kept under natural photoperiod in breeding facilities consisting of $300 \mathrm{~m}^{2}$ pens with barriers to avoid visual contact between pairs. Semen was collected from males of both species twice a week using the massage method (Quinn and Burrows, 1937), with specific modifications for cranes (Gee and Temple, 1978; Gee, 1983), and ejaculates on a given day were pooled before transport to the laboratory. Semen was maintained at room temperature until dilution for cryopreservation.

\subsection{Cryodiluent composition and treatments}

Turkey and crane semen were diluted with different extenders based on known species-specific requirements for extender components and osmolality (Sexton, 1979; Gee and Mirande, 1996; Blanco et al., 2008). The base cryodiluent for turkey semen was Beltsville Poultry Semen Extender (BPSE; Continental Plastic Corporation, Delavan, WI) modified by adjusting the osmolality to $310 \mathrm{mOsm}$. Components for the base crane cryodiluent (Blanco et al., 2008) are shown in Table 1 . For each species, cryodiluents containing one of five DMA concentrations (6\%, 10\%, $18 \%$, $24 \%$ and $26 \%$ ) were compared with and without ATP or osmoprotectants. The ATP concentrations that were evaluated were the equivalent of $1.5 \%, 3.0 \%$ and $6.0 \%$ or 30,60 and $118 \mathrm{mM}$, respectively. The osmoprotectants sucrose, trehalose and betaine hydrochloride were evaluated at the following final concentrations: (1) sucrose $(8 \%$ or $0.2 \mathrm{M}$, turkey; $5 \%$ or $0.1 \mathrm{M}$, crane); (2) $0.1 \mathrm{M}$ sucrose and $0.1 \mathrm{M}$ trehalose combined (both species); and (3) $0.1,0.2$ or $0.4 \mathrm{M}$ betaine hydrochloride (both species). Based on preliminary data, a higher concentration of sucrose was used for turkey sperm treatments than crane sperm treatments (Blanco et al., unpublished data). Stock solutions of each cryodiluent were prepared to yield these final concentrations 
based upon species-specific semen dilutions in turkey ( $1: 1$; Sexton, 1976) and crane (1:2; Gee and Mirande, 1996). For example, the final concentration of the $6 \% \mathrm{DMA} / 100 \mathrm{mM}$ betaine hydrochloride treatment would use a stock solution of $12 \% \mathrm{DMA} / 200 \mathrm{mM}$ betaine hydrochloride for turkey sperm and 18\% DMA/300 mM betaine hydrochloride for crane sperm. A total of 45 cryodiluent treatment combinations were evaluated for each species. Unless specified otherwise, all chemicals were obtained from Sigma Aldrich (St. Louis, MO).

\subsection{Semen cryopreservation and thawing}

Pooled turkey or crane semen was aliquoted and diluted $1: 1$ and $1: 2$, respectively, with 1 of the 45 cryodiluent treatments and equilibrated for $25 \mathrm{~min}$ at room temperature $\left(25^{\circ} \mathrm{C}\right)$, followed by a $15 \mathrm{~min}$ equilibration at $4{ }^{\circ} \mathrm{C}$. Cooled semen ( $100 \mu \mathrm{L}$ volume) was packaged into $0.5 \mathrm{~mL}$ cryovials and cryopreserved using a programmable freezer (Model 2100; Custom Biogenic Systems, Romeo, MI) and the following freezing rates: $1{ }^{\circ} \mathrm{C} / \mathrm{min}$ from $+4{ }^{\circ} \mathrm{C}$ to $-20^{\circ} \mathrm{C}$, followed by $2.5^{\circ} \mathrm{C} / \mathrm{min}$ from $-20^{\circ} \mathrm{C}$ to $-80^{\circ} \mathrm{C}$. Upon reaching $-80^{\circ} \mathrm{C}$, cryovials were plunged into liquid nitrogen. Frozen semen was stored for a minimum of 4 week before being thawed for evaluation. Cryovials were placed in a $+4{ }^{\circ} \mathrm{C}$ icewater bath for 5 min to thaw. Semen cryopreservation trials were run in duplicate for each species and treatment.

\subsection{Sperm motility and viability assessment}

Sperm motility was evaluated using the hanging drop method (Wishart and Wilson, 1997) and phase contrast microscopy (Zeiss Axiolab; Carl Zeiss, Inc., Thornwood, $\mathrm{NY}$ ). In brief, $20 \mu \mathrm{L}$ of thawed semen was diluted 1:2 with motility buffer (Froman and McLean, 1996) and warmed to $41^{\circ} \mathrm{C}$ for $5 \mathrm{~min}$ before observation. Sperm viability was assessed in diluted suspensions from both species using the nigrosin-eosin live/dead stain combination (Gee and Mirande, 1996). Slides were evaluated microscopically using $40 \times$ magnification. Live, membrane-intact sperm were clear in appearance, whereas dead sperm stained red to purple. A total of 200 sperm were assessed per slide.

\subsection{Statistical analysis}

Within species, one factor and multifactor ANOVA (SAS version 9.2; SAS Institute, Inc., Cary, NC) was performed, and the a priori determined significance level was $<0.05$. Data were tested for normality using the Shapiro-Wilk test. Values reported are non-transformed and means are expressed as SEM.

\section{Results}

\subsection{Post-thaw sperm motility}

The post-thaw motility of turkey and crane sperm frozen only with DMA was greater $(P<0.05)$ in the $6 \%, 10 \%$ and $18 \%$ treatments than the $24 \%$ or $26 \%$ treatments, with motility ranging from $0 \%$ to $18 \%$ for turkey and $20 \%$ to $39 \%$ for crane sperm. Inclusion of sugars as osmoprotectants in the cryodiluent improved $(P<0.05)$ post-thaw motility of turkey sperm (Fig. 1). In particular, the post-thaw motility of turkey sperm in the combined sucrose/trehalose treatments was greater $(P<0.05)$ for all DMA concentrations; while this benefit occurred only at the $6 \%$ and $10 \%$ DMA concentrations with sucrose alone (Fig. 1). Only the lowest concentration of betaine hydrochloride $(0.1 \mathrm{M})$ or ATP $(30 \mathrm{mM})$ improved $(P<0.05)$ post-thaw turkey sperm motility, and only at lower DMA (6\%, 10\% for betaine hydrochloride; $10 \%$ for ATP) concentrations (Fig. 2).

Crane sperm differed in post-thaw motility response in the presence of the osmoprotectants and extracellular ATP. Neither sucrose nor the sucrose/trehalose combination improved the post-thaw motility of crane sperm (range, 20-26\%) above the DMA controls (range, 22-25\%; $P>0.05)$. Similarly, none of the betaine hydrochloride treatments improved post-thaw motility of crane sperm (range, $18-21 \% ; P>0.05)$. In complete contrast to turkey sperm,

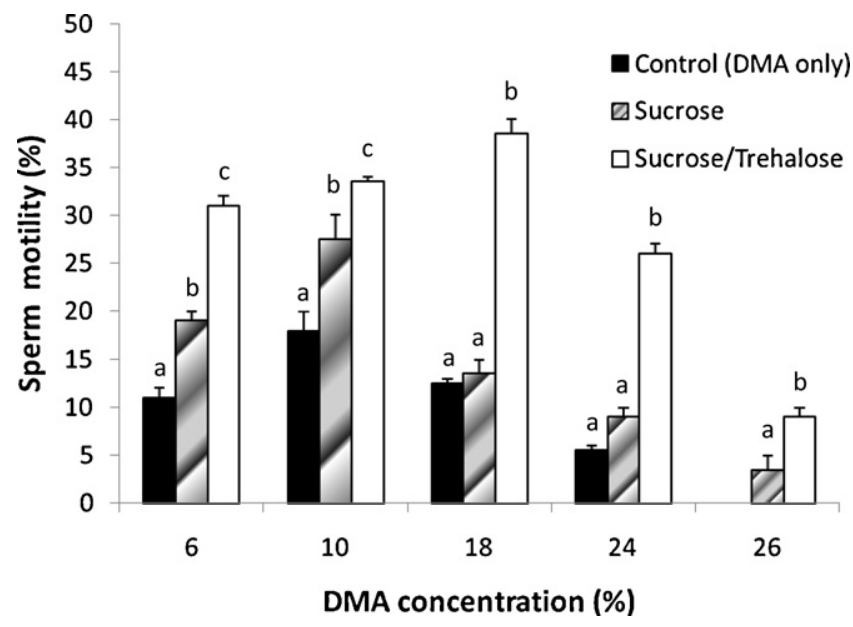

Fig. 1. Comparative increase in turkey sperm motility after thawing conferred by the addition of $8 \%$ sucrose or the combination of sucrose and trehalose ( $5 \%$ each). Within dimethylacetamide (DMA) concentration, different superscripts indicate that means differed $(P<0.05)$. Note: Sperm motility was $0 \%$ in the 26\% DMA control. 


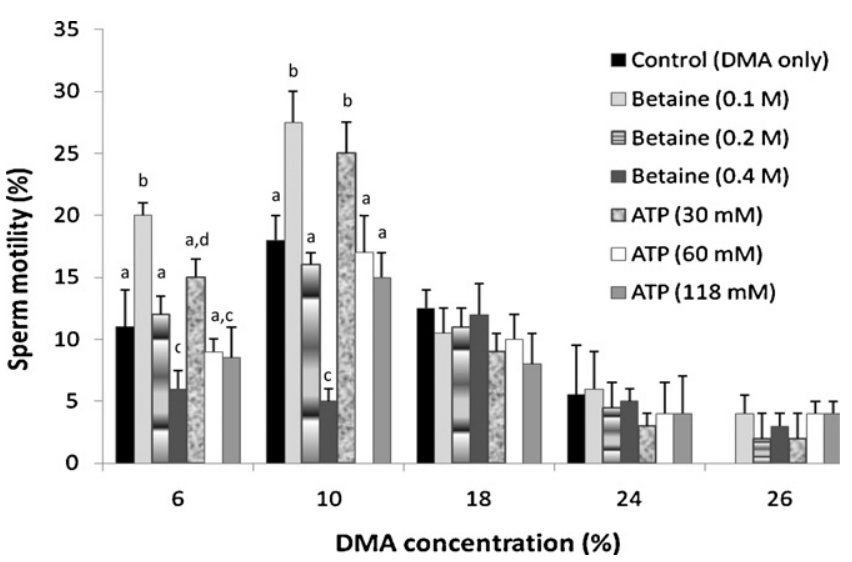

Fig. 2. Influence of supplemental betaine hydrochloride or ATP on post-thaw motility of turkey sperm. Within dimethylacetamide (DMA) concentration, different superscripts indicate that means differed $(P<0.05)$. Note: Sperm motility was 0\% in the 26\% DMA control.

the greatest $(P<0.05)$ post-thaw motility was observed in crane sperm frozen with a combination of $24 \%$ DMA and $30 \mathrm{mM}$ ATP (Fig. 3). Significant increases in crane sperm motility also were observed after the addition of $30 \mathrm{mM}$ ATP at DMA concentrations ranging from $18 \%$ to $26 \%$ compared to the control $(P<0.05)$.

\subsection{Post-thaw sperm viability}

Table 2 depicts the post-thaw viability means for turkey sperm. When frozen with DMA alone, turkey sperm viability ranged from $11.5 \%$ to $32.5 \%$, with the greatest number of viable sperm observed for the $18 \%$ treatment and the least measured in the $26 \%$ treatment $(P<0.05)$. The addition of sucrose or sucrose/trehalose did not improve sperm viability above the DMA controls $(P>0.05)$. With the exception of the $30 \mathrm{mM} \mathrm{ATP} / 24 \%$ DMA treatment, the inclusion of ATP either maintained $(P>0.05)$ or decreased $(P<0.05)$ sperm viability compared to DMA controls. Interestingly, the use of $0.1 \mathrm{M}$ betaine hydrochloride in the cryodiluent improved $(P<0.05)$ the post-thaw viability of turkey sperm for all DMA treatments. Moreover, the greatest post-thaw viability $(47.0 \pm 1.0 \%)$ was observed for the $24 \%$ DMA treatment containing $0.1 \mathrm{M}$ betaine hydrochloride, nearly a $15 \%$ increase above the highest post-thaw viability measured in the DMA controls ( $32.5 \pm 1.5 \%$ ).

The response of thawed crane sperm viability differed from that of the turkey. For the crane, the highest post-thaw viability $(77 \pm 3 \%$ ) was observed in the $26 \%$ DMA control, with no enhancement $(P>0.05)$ offered by any osmoprotectant or ATP treatment above the 26\% DMA control (Table 3). For the sucrose and sucrose/trehalose treatments, post-thaw sperm viability improved in the $6-18 \%$ DMA treatments compared to the 6-18\% DMA controls $(P<0.05)$; however, the greatest number of viable sperm was only $69.0 \pm 2.5 \%$. At all concentrations tested, betaine hydrochloride improved $(P<0.05)$ post-thaw sperm viability over some corresponding DMA controls, but the greatest percentage of viable sperm in any betaine hydrochloride treatment $(0.1 \mathrm{M}$ and $24 \% \mathrm{DMA}, 70 \pm 3 \%)$ was still lower than that observed with 26\% DMA alone. Addition of $30 \mathrm{mM}$ ATP improved sperm viability $(P<0.5)$ for all DMA treatments compared to the corresponding DMA controls, especially $18 \%$ (no ATP, $46.9 \pm 1.5 ; 30 \mathrm{mM}$ ATP, $78.0 \pm 3.5 \%$ ) and $24 \%$ DMA (no ATP, $60.0 \pm 1.5 ; 30 \mathrm{mM}$ ATP, $77.0 \pm 3.5$ ). Addition of 60 or $118 \mathrm{mM}$ ATP generally was not beneficial for crane sperm viability post-thaw (Table 3).

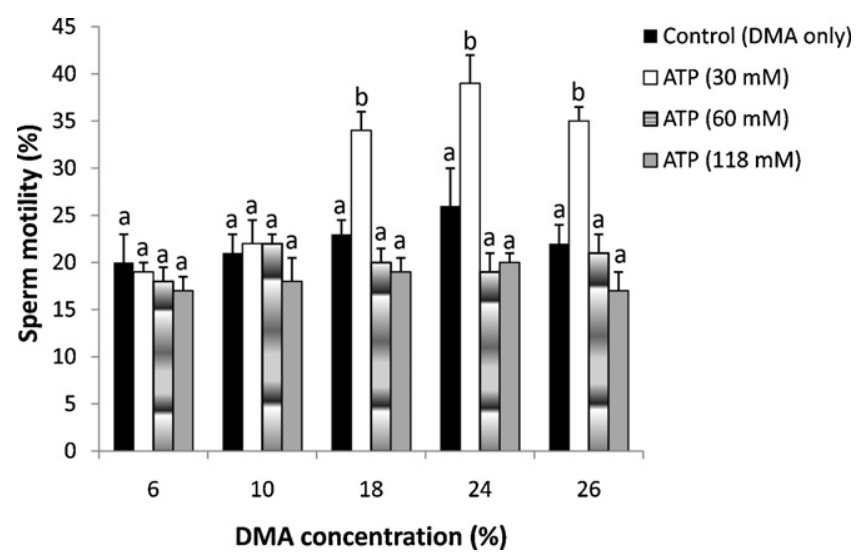

Fig. 3. Influence of supplemental ATP on post-thaw motility of crane sperm. Within dimethylacetamide(DMA) concentration, different superscripts indicate that means differed $(P<0.05)$. 
Table 2

Influence of cryodiluent composition on post-thaw viability of turkey sperm.

\begin{tabular}{|c|c|c|c|c|c|c|c|c|c|}
\hline $\begin{array}{l}\text { Dimethylacetamide } \\
\text { (DMA; \%) }\end{array}$ & $\begin{array}{l}\text { Control } \\
\text { (DMA only) }\end{array}$ & Sucrose & $\begin{array}{l}\text { Sucrose/ } \\
\text { trehalose }\end{array}$ & $\begin{array}{l}\text { ATP } \\
(30 \mathrm{mM})\end{array}$ & $\begin{array}{l}\text { ATP } \\
(60 \mathrm{mM})\end{array}$ & $\begin{array}{l}\text { ATP } \\
(118 \mathrm{mM})\end{array}$ & $\begin{array}{l}\text { Betaine } \\
(0.1 \mathrm{M})\end{array}$ & $\begin{array}{l}\text { Betaine } \\
(0.2 \mathrm{M})\end{array}$ & $\begin{array}{l}\text { Betaine } \\
(0.4 \mathrm{M})\end{array}$ \\
\hline 6 & $22.0 \pm 3.0^{a}$ & $23.0 \pm 2.5^{\mathrm{a}}$ & $27.5 \pm 2.0^{\mathrm{a}}$ & $20.0 \pm 1.0^{\mathrm{a}}$ & $18.5 \pm 1.5^{\mathrm{a}, \mathrm{b}}$ & $15.5 \pm 1.5^{b}$ & $32.5 \pm 1.5^{c}$ & $19.0 \pm 1.0^{\mathrm{a}, \mathrm{b}}$ & $33.5 \pm 2.5^{c}$ \\
\hline 10 & $26.0 \pm 2.0^{\mathrm{a}}$ & $24.0 \pm 2.0^{\mathrm{a}}$ & $27.5 \pm 2.0^{\mathrm{a}}$ & $30.5 \pm 2.5^{a}$ & $29.5 \pm 2.0^{\mathrm{a}}$ & $14.0 \pm 1.0^{\mathrm{b}}$ & $33.5 \pm 2.5^{c}$ & $25.0 \pm 3.0^{\mathrm{a}}$ & $27.0 \pm 2.0^{\mathrm{a}}$ \\
\hline 18 & $32.5 \pm 1.5^{\mathrm{a}}$ & $39.0 \pm 2.5^{\mathrm{a}}$ & $31.5 \pm 2.5^{\mathrm{a}}$ & $32.0 \pm 2.0^{\mathrm{a}}$ & $34.5 \pm 1.5^{\mathrm{a}}$ & $17.5 \pm 2.5^{b}$ & $41.5 \pm 1.5^{c}$ & $34.0 \pm 2.0^{\mathrm{a}}$ & $35.5 \pm 2.5^{\mathrm{a}}$ \\
\hline 24 & $26.0 \pm 4.0^{\mathrm{a}}$ & $20.5 \pm 3.0^{\mathrm{a}}$ & $24.5 \pm 3.0^{\mathrm{a}}$ & $36.0 \pm 3.0^{b}$ & $32.0 \pm 2.0^{\mathrm{a}}$ & $15.0 \pm 1.0^{c}$ & $47.0 \pm 1.0^{\mathrm{d}}$ & $15.5 \pm 2.5^{c}$ & $27.0 \pm 3.0^{\mathrm{a}}$ \\
\hline 26 & $11.5 \pm 2.5^{\mathrm{a}}$ & $12.0 \pm 1.0^{\mathrm{a}}$ & $18.0 \pm 2.5^{\mathrm{a}}$ & $4.5 \pm 1.5^{\mathrm{b}}$ & $12.0 \pm 2.0^{\mathrm{a}}$ & $7.0 \pm 1.5^{\mathrm{a}, \mathrm{b}}$ & $45.0 \pm 2.0^{d}$ & $24.0 \pm 1.0^{c}$ & $29.0 \pm 1.0^{c}$ \\
\hline
\end{tabular}

a-c: within rows, different superscripts indicate that means differed $(P<0.05)$.

\section{Discussion}

A milestone in reproductive science was the discovery of the beneficial effects of the permeating agent glycerol for protecting fowl sperm during cryopreservation (Polge, 1951). Ironically, it was later determined that glycerol also has contraceptive properties at the concentrations needed to confer cryoprotection (Neville et al., 1971; Sexton, 1975). This stimulated investigations of alternative permeating cryoprotectants, with DMA having been described as the most promising in both domestic (Broerski, 1989) and nondomestic avian species (Brock and Bird, 1991). Even so, it has appeared that DMA often yields mixed results in postthaw survival of bird sperm. The present study has provided one reason - variability between species in sensitivity and responsiveness to the protective capacities of DMA. For example, we demonstrated that lower DMA concentrations (10-18\%) provided more cryoprotection for turkey sperm, whereas substantially higher levels (26\%) were necessary for crane sperm.

We are strong advocates for this cross-species comparative approach in understanding the mechanisms regulating cell sensitivity to low temperatures. In an earlier study, remarkable variations among domestic fowl and three birds of prey to osmotic stress were elucidated (Blanco et al., 2000). Sperm from raptor species (imperial eagle, peregrine falcon, golden eagle) were much more tolerant of hyperosmotic conditions than sperm from poultry species (chicken, turkey). Likewise, a more recent study revealed that sperm from the sandhill crane were vastly more tolerant to osmotic stress than the same cells from the common turkey (Blanco et al., 2008). These differences among species are no doubt related to a combination of natural evolutionary differences and selection pressures over time. Whatever the origin, clearly the less osmo-tolerant turkey sperm benefit the most from the supplementation with osmoprotectants. The natural osmoprotectants examined here have been studied previously by others (Zhang et al., 2001; Aboagla and Terada, 2003; Edwards et al., 2007;
Gutiérrez-Pérez et al., 2009) with the presumption that they somehow stabilize cellular membranes (Rudolph and Crowe, 1985).

Normal processes associated with cryopreservation such as dehydration and ice crystal formation can cause cracks in and/or lysis of membranes. Lower organisms have evolved to address this instability naturally through the production of osmoprotectants, like trehalose, that prevent fusion of the phospholipid vesicles within the plasma membrane (Rudolph and Crowe, 1985; Aisen et al., 2002). Dalimata and Graham (1997) first discovered that trehalose added to a DMA-based freezing medium could prevent significant damage incurred by freezing sperm of a higher mammal (in this case, the rabbit). The current study revealed that a benefit to turkey sperm motility was extended by sucrose alone, but a more superior response was achieved in the presence of the combination of trehalose and sucrose. The effect, however, was DMAconcentration dependent ( $18 \%$ being most desirable) and this advantage was not conferred to turkey sperm viability after thawing. Interestingly, this discordance between sperm motility and viability in response to trehalose also has been reported for bull sperm (Chen et al., 1993). In this previous study, it was speculated that, even though the plasma membrane was damaged, the motility generating apparatus was still functional and could support bull sperm motility because exogenous substrates could pass through the 'leaky' membrane. This seems a plausible explanation for the improvement in turkey sperm motility without a subsequent increase in viability in the present study. Other theories postulate that the additive benefits of trehalose stems from the formation of hydrogen bonds between the sugar hydroxyl groups and the phospholipid polar head groups (Crowe and Crowe, 1985), which provokes a substitution for water molecules under dehydrated conditions that would protect cells from the effects of hypertonicity more efficiently than sucrose alone. In the crane, the benefits of sugar osmoprotectants on sperm viability were seen only at lower DMA concentrations. The lack of osmo-

Table 3

Influence of cryodiluent composition on post-thaw viability of crane sperm.

\begin{tabular}{|c|c|c|c|c|c|c|c|c|c|}
\hline $\begin{array}{l}\text { Dimethylacetamide } \\
\text { (DMA; \%) }\end{array}$ & $\begin{array}{l}\text { Control } \\
\text { (DMA only) }\end{array}$ & Sucrose & $\begin{array}{l}\text { Sucrose/ } \\
\text { trehalose }\end{array}$ & $\begin{array}{l}\text { ATP } \\
(30 \mathrm{mM})\end{array}$ & $\begin{array}{l}\text { ATP } \\
(60 \mathrm{mM})\end{array}$ & $\begin{array}{l}\text { ATP } \\
(118 \mathrm{mM})\end{array}$ & $\begin{array}{l}\text { Betaine } \\
(0.1 \mathrm{M})\end{array}$ & $\begin{array}{l}\text { Betaine } \\
(0.2 \mathrm{M})\end{array}$ & $\begin{array}{l}\text { Betaine } \\
(0.4 \mathrm{M})\end{array}$ \\
\hline 6 & & $43.0 \pm 1.5^{b}$ & $57.5 \pm 2.0^{\mathrm{b}}$ & $58.5 \pm 1.0^{b}$ & $43.5 \pm 2.5^{b}$ & & $44.5 \pm 1.5^{b}$ & $48.0 \pm 1.0^{\mathrm{b}}$ & \\
\hline 10 & $48.5 \pm 5.0^{\mathrm{a}}$ & $54.0 \pm 2.0^{\mathrm{a}}$ & $67.5 \pm 3.0^{\mathrm{b}}$ & $65.0 \pm 2.5^{b}$ & $35.0 \pm 2.0^{c}$ & $29.0 \pm 1.0^{c}$ & $55.5 \pm 1.5^{\mathrm{a}}$ & $51.5 \pm 1.5^{\mathrm{a}}$ & $50.0 \pm 1.5^{\mathrm{a}}$ \\
\hline 18 & $46.0 \pm 1.5^{\mathrm{a}}$ & $69.0 \pm 2.5^{\mathrm{b}, \mathrm{c}}$ & $61.5 \pm 1.5^{\mathrm{b}, \mathrm{c}}$ & $78.0 \pm 3.5^{\mathrm{b}, \mathrm{c}}$ & $54.0 \pm 1.0^{\mathrm{b}}$ & $21.0 \pm 3.0^{\mathrm{d}}$ & $46.5 \pm 2.5^{\mathrm{a}}$ & $56.5 \pm 1.5^{\mathrm{b}}$ & $61.5 \pm 2.5^{b}$ \\
\hline 24 & $60.0 \pm 1.5^{\mathrm{a}}$ & $60.5 \pm 3.0^{\mathrm{a}}$ & $54.5 \pm 2.0^{\mathrm{a}}$ & $77.0 \pm 3.0^{\mathrm{b}}$ & $65.0 \pm 2.0^{\mathrm{a}}$ & $33.0 \pm 3.0^{c}$ & $70.0 \pm 3.0^{\mathrm{b}}$ & $59.5 \pm 2.5^{\mathrm{a}}$ & $58.0 \pm 2.5^{\mathrm{a}}$ \\
\hline 26 & $77.0 \pm 3.0^{\mathrm{a}}$ & $72.0 \pm 1.0^{\mathrm{a}, \mathrm{b}}$ & $68.0 \pm 1.5^{b}$ & $73.5 \pm 3.5^{a}$ & $55.5 \pm 0.5^{c}$ & $40.5 \pm 8.5^{d}$ & $69.5 \pm 1.5^{\mathrm{b}}$ & $60.0 \pm 3.0^{c}$ & $54.5 \pm 0.5^{c}$ \\
\hline
\end{tabular}

a-c: within rows, different superscripts indicate that means differed $(P<0.05)$. 
protectant effect at higher DMA concentrations could be explained in terms of critical sperm osmolality ranges. Supplementing with both sucrose and trehalose probably increased the osmolality of the extracellular medium, which was tolerated by crane sperm at lower DMA concentrations. It is possible that when the DMA concentration increased, the parallel elevation in osmolality entered the critical range for crane sperm, thereby reducing sperm viability. Our earlier finding of a naturally low osmotolerance of turkey sperm to hypertonicity (Blanco et al., 2008) supports this theory.

Cooling rate also may have been a factor influencing the greater viability in crane compared to turkey sperm in the presence of sugars and the lower DMA concentration. It is well established that sucrose and trehalose confer the most cryoprotection during fast cooling events. Previous studies indicate predilection of crane sperm for slower cooling likely is due to a lower water permeability coefficient compared to turkey sperm (Blanco et al., 1999). Therefore, we suspect that the presence of these sugars assists in sustaining attenuated membrane permeability in the presence of rapid water efflux that threatens to disrupt cellular form and function. The lack of a 'sugar effect' with turkey sperm may be related to lower membrane sensitivity to cooling rate.

Supplementing turkey sperm with $0.1 \mathrm{M}$ betaine hydrochloride produced the best post-thaw viability, even with the greater (24\%) DMA concentration. While betaine hydrochloride also was beneficial for crane sperm viability (at 0.1 or $0.2 \mathrm{M}$ ), the effect was exerted at the lower DMA concentrations (6-18\%). Thus, our findings revealed that the interactive benefit between a cryoprotectant and natural osmoprotectant was conserved between two bird species, but different in terms of concentration dependency. It also was important that we demonstrated the value of betaine hydrochloride on the more holistic assessment of 'sperm viability' as previous studies (in mammals) have only examined the impact of betaine hydrochloride on sperm motility (Sánchez-Partida et al., 1992; Trimeche et al., 1999; Zhang et al., 2001).

Extracellular ATP occasionally has been used in human fertility cases, mostly to improve post-thaw viability in patients experiencing pre-freeze motility compromise (Edwards et al., 2007). Mouse studies have suggested that the mechanism of action is that extracellular ATP induces a rapid increase in intracellular calcium concentrations that facilitate hyperactive motility (Rodríguez-Miranda et al., 2008). Interestingly, this type of supplementation had a significant positive impact on crane but not turkey sperm. This, in turn, may explain one of the reasons for failed post-thaw viability in crane gametes that have this unusually highly permeable plasma membrane. That trait could be resulting in excessive ATP leakage and depletion of intracellular stores that is mitigated by extracellular supplementation. Post-thaw ATP concentrations have been correlated positively with bull sperm motility, and dead sperm have no ATP (Soderquist and Larson, 1985). This issue also has arisen in studies of ram sperm cryopreservation; specifically these cells being poorly permeable for extracellular ATP uptake until the thawed membrane reaches a temperature that causes appropriate structural rearrangements to facilitate diffusion (Holt et al., 1992). Although the present study was not designed to examine this mechanism, it is noteworthy that our post-thaw motility evaluations were conducted at an elevated temperature of $21^{\circ} \mathrm{C}$.

Cryopreservation of living germplasm for the purpose of storing and then rejuvenating the male genome for propagation is one of the most complex challenges in reproductive science and animal management. One priority is to continue to build on fundamental knowledge about these processes in well-studied domestic fowl to further enhance contemporary protocols and production efficiency. Equally important is determining how to apply this methodology to the hundreds of rare bird species that could benefit in terms of genetic management and conservation (Blanco et al., 2000; Saint Jalme et al., 2003; Umapathy et al., 2005), as cryopreservation protocols may not be transferred successfully from domestic to non-domestic avian species. Indeed, the present study identified species-specific differences of the cryoprotectant DMA in combination with natural osmoprotectants and supplemental ATP on the cryosurvival of bird sperm. In summary, the non-permeating osmoprotectants sucrose, trehalose and betaine hydrochloride did not increase crane sperm cryosurvival (e.g. motility, viability); whereas inclusion of $30 \mathrm{mM}$ ATP generally improved the postthaw viability and motility of crane sperm at greater DMA concentrations. Form these data, it is evident that ATP is the only supplement evaluated that benefits the cryosurvival of crane sperm. For the turkey, inclusion of the natural cryoprotectant betaine hydrochloride was extremely beneficial for sperm viability and motility postthaw. Further, it is highly likely that a combination of 10-18\% DMA, sucrose/trehalose, $0.1 \mathrm{M}$ betaine hydrochloride and/or $30 \mathrm{mM}$ ATP will enable turkey sperm to better withstand the freeze/thaw process. Findings in the present study confirm that each bird species of interest will require significant amounts of basic research to develop successful sperm cryopreservation protocols.

\section{References}

Aboagla, E.M., Terada, T., 2003. Trehalose-enhanced fluidity of the goat sperm membrane and its protection during freezing. Biol. Reprod. 69, $1245-1250$.

Aisen, E., Medina, V., Venturino, A., 2002. Cryopreservation and post thawed fertility of ram semen frozen in different trehalose concentrations. Theriogenology 57, 1801-1808.

Blanco, J.M., Gee, G., Wildt, D.E., Donoghue, A.M., 2000. Species variation in osmotic, cryoprotectant, and cooling rate tolerance in poultry, eagle, and peregrine falcon spermatozoa. Biol. Reprod. 63, 1164-1171.

Blanco, J.M., Long, J.A., Gee, G., Donoghue, A.M., Wildt, D.E., 2008. Osmotic tolerance of avian spermatozoa: influence of time, temperature, cryoprotectant and membrane ion pump function on sperm viability. Cryobiology 56, 8-14

Blanco, J.M., Tselutin, K., Gee, G.F., Wildt, D.E., Donoghue, A.M., 1999. Comparative cryopreservation of poultry sperm: characterization of sperm survival after rapid and slow freezing methods and the use of $6 \%$ dimethylacetamide as a cryoprotectant for chicken and turkey sperm. In: BARC Symposium , Beltsville, MD.

Brock, M.K., Bird, D.M., 1991. Pre-freeze and post-thaw effects of glycerol and dimethylacetamide on motility and fertilizing ability of American kestrel (Falco sparverius) spermatozoa. J. Zoo Wildl. Med. 22, 453-459.

Broerski, A.V., 1989. Cryopreservation of poultry semen, a survey of the foreign literature. Sel'skokzyaistvennaya Biologiya 2, 33-39. 
Chełmońska, B., Łukaszewicz, E., Kowalczyk, A., Jerysz, A., 2006. The effect of DMA level on morphology and fertilizing ability of Japanese quail (Coturnix japonica) spermatozoa. Theriogenology 65, 451-458.

Chen, Y., Foote, R.H., Brockett, C.C., 1993. Effect of sucrose, trehalose, hypotaurine, taurine and blood serum on survival of frozen bull sperm. Cryobiology 30, 423-431.

Cleland, D., Krader, P., McCree, C., Tang, J., Emerson, D., 2004. Glycine betaine as a cryoprotectant for prokaryotes. J. Microbiol. Methods 58 31-38.

Crowe, J.H., Crowe, L.M., 1985. Effect of dehydration on membranes and membrane stabilization at low water activities. In: Chapman, D. (Ed.), Biological Membranes, vol. 5. Academic Press, New York/London.

Csonka, L.N., Hanson, A.D., 1991. Prokaryotic osmoregulation: genetics and physiology. Ann. Rev. Microbiol. 45, 569-606.

Dalimata, A.M., Graham, J.K., 1997. Cryopreservation of rabbit spermatozoa using acetamide in combination with trehalose and methylcellulose. Theriogenology 48, 831-841.

Edwards, S.E., Buffone, M.G., Knee, G.R., Rossato, M., Bonanni, G., Masiero, S., Ferasin, S., Gerton, G.L., Moss, S.B., Williams, C.J., 2007. Effects of extracellular adenosine $5^{\prime}$-triphosphate on human sperm motility. Reprod. Sci. 14, 655-666.

Froman, D.P., McLean, D.J., 1996. Objective measurement of sperm motility based upon sperm penetration of Accudenz. Poult. Sci. 75, 776-784

Gee, G.F., Temple, S.A., 1978. Artificial insemination for breeding nondomestic birds. Symp. Zool. Soc. Lond. 43, 51-72.

Gee, G.F., 1983. Avian artificial insemination and semen preservation. In: Jean Delacour/IFCB Symposium on Breeding Birds in Captivity ,. $\mathrm{N}$. Hollywood, CA, pp. 375-398.

Gee, G.F., Mirande, C.M., 1996. Crane artificial insemination. In: Ellis, D.H., Gee, G.F., Mirande, C.M. (Eds.), Cranes: Their Biology, Husbandry and Conservation. U.S. Department of the Interior, National Biological Service/International Crane Foundation, Washington, DC/Baraboo, WI, pp. 205-217

Gutiérrez-Pérez, O., Juárez-Mosqueda, M.L., Carvajal, S.U., Ortega, M.E. 2009. Boar spermatozoa cryopreservation in low glycerol/trehalose enriched freezing media improves cellular integrity. Cryobiology 58 , 287-292.

Holt, W.V., Head, F., North, R.D., 1992. Freeze-induced membrane damage in ram spermatozoa is manifested after thawing: observations with experimental cryomicroscopy. Biol. Reprod. 46, 1086-1094.

Holt, W.V., 2000. Basic aspects of frozen semen storage. Anim. Reprod. Sci. $62,3-22$

Jain, N.K., Roy, I., 2009. Effect of trehalose on protein structure. Protein Sci. 18, 24-36.

Kowalczyk, A., 2008. The effect of cryopreservation process on morphology and fertilising ability of Japanese quail (Coturnix japonica) spermatozoa. Cryo Lett. 29, 199-208.

Lippert, K., Galinski, E.A., Trüper, H.G., 1993. Biosynthesis and function of trehalose in Ectothiorhodospira halochloris. Antonie Van Leeuwenhoek 63, 85-91.

Lloyd, A.W., Olliff, C.J., Rutt, K.J., 1994. A study of modified betaines as cryoprotective additives. J. Pharm. Pharmacol. 46, 704-707.

Neville, W.J., Macpherson, J.W., Reinhart, B., 1971. The contraceptive action of glycerol in chickens. Poult. Sci. 50, 1411-1415.

Ochkur, S.I., Evgeniy, Kopika, F., Suraj, P.F., Grishchenko, V.I., 1994. The influence of cryopreservation on parameters of energetic metabolism and motility of fowl spermatozoa. Cryobiology 31, 239-244.

Oderkirk, F.H., Buckland, A., 1977. A comparison of diluents and cryopreservatives for freezing turkey semen. Poult. Sci. 56, 1861-1867.

Polge, C., 1951. Functional survival of fowl spermatozoa after freezing at $-79^{\circ} \mathrm{C}$. Nature $167,949-950$.
Quinn, J.P., Burrows, W.H., 1937. Artificial insemination of fowls. J. Hered $27,31-37$.

Rodríguez-Miranda, E., Buffone, M.G., Edwards, S.E., Ord, T.S., Lin, K., Sammel, M.D., Gerton, G.L., Moss, S.B., Williams, C.J., 2008. Extracellular adenosine 5 '-triphosphate alters motility and improves the fertilizing capability of mouse sperm. Biol. Reprod. 79, 164-171.

Rudolph, A.S., Crowe, J.H., 1985. Membrane stabilization during freezing: the role of two natural cryoprotectants, trehalose and proline. Cryobiology 22, 367-377.

Sánchez-Partida, L.G., Maxwell, W.M., Paleg, L.G., Setchell, B.P., 1992. Proline and glycine betaine in cryoprotective diluents for ram spermatozoa. Reprod. Fertil. Dev. 4, 113-118.

Saint Jalme, M., Lecoq, R., Seigneurin, F., Blesbois, E., Plouzeau, E., 2003. Cryopreservation of semen from endangered pheasants: the first step towards a cryobank for endangered avian species. Theriogenology 59, $875-888$.

Sexton, T.J., 1975. Comparison of various cryoprotective agents on washed chicken spermatozoa. 5. Effect of glucose, sucrose and polyvinylpyrrolidone. Poult. Sci. 54, 1297-1299.

Sexton, T.J., 1976. Studies on the dilution of turkey semen. Br. Poult. Sci. $17,179-184$

Sexton, T.J., 1979. Preservation of poultry semen. In: Hawk, H.W. (Ed.), Animal Reproduction. John Wiley \& Sons, New York, NY, pp. 159-170.

Sexton, T.J., 1980. Optimal rates for cooling chicken semen from +5 to $-196^{\circ}$ C. Poult. Sci. 59, 2765-2770.

Soderquist, L., Larson, K., 1985. Relationship between ATP content and post-thaw motility in bull semen. Acta Vet. Scand. 26, 308-312.

Tai, J.J., Chen, J.C., Wu, K.C., Wang, S.D., Tai, C., 2001. Cryopreservation of gander semen. Br. Poult. Sci. 42, 384-388.

Thompson, K.A., Richa, J., Liebhaber, S.A., Storey, B.T., 2001. Dialysis addition of trehalose/glycerol cryoprotectant allows recovery of cryopreserved mouse spermatozoa with satisfactory fertilizing ability as assessed by yield of live young. J. Androl. 22, 339-344.

Trimeche, A., Yvon, J.M., Vidament, M., Palmer, E., Magistrini, M., 1999. Effects of glutamine, proline, histidine and betaine on post-thaw motility of stallion spermatozoa. Theriogenology 52, 181-191.

Tselutin, K., Seigneurin, F., Blesbois, E., 1999. Comparison of cryoprotectants and methods of cryopreservation of fowl spermatozoa. Poult. Sci. 78, 586-590.

Umapathy, G., Sontakke, S., Reddy, A., Ahmed, S., Shivaji, S., 2005. Semen characteristics of the captive Indian white-backed vulture (Gyps bengalensis). Biol. Reprod. 73, 1039-1045.

Wishart, G.J., Wilson, Y.I., 1997. Sperm motility and metabolism. I. Visual scoring of motility using the hang drop method. In: Bakst, M.R., Cecil, H.C. (Eds.), Techniques for Semen Evaluation, Semen Storage, and Fertility Determination. Poult. Sci. Assoc. Inc., Savoy, IL, pp. 46-47.

Woelders, H., Matthijs, A., Engel, B., 1997. Effects of trehalose and sucrose, osmolality of the frozen medium, and cooling rate on viability and intactness of bull sperm after freezing and thawing. Cryobiology 35, 93-105.

Yamashiro, H., Narita, K., Sugimura, S., Han, Y.J., Sugawara, A., Morohaku, K., Nakazato, F., Konno, T., Yoshida, M., Sato, E., 2007. Trehalose enhanced the freezability of Poodle dog sperm collected by an artificial vagina (AV). Anim. Reprod. Sci. 102, 165-171.

Zhang, B.R., Buhr, M., Kroetschd, T., Leibo, S.P., 2001. Glycine betaine improves survival of fresh bovine spermatozoa. Reprod. Fertil. Dev. 13, 187-192. 